\title{
Simulation and Experimental Investigation of Modulation Techniques for BLDC Motor Control
}

\author{
Ivan Maradzhiev, Tsvetana Grigorova*, Emil Dinkov \\ Department of Electronics, Technical University of Sofia, Bulgaria
}

Received November 16, 2019; Revised December 24, 2019; Accepted December 30, 2019

Copyright $\mathrm{C} 2020$ by authors, all rights reserved. Authors agree that this article remains permanently open access under the terms of the Creative Commons Attribution License 4.0 International License

\begin{abstract}
The following paper investigates and analyses the electromagnetic processes in an electrical drive system composed of a power source, a power inverter and a brushless dc (BLDC) motor using known pulse-width modulation (PWM) methods. Investigated modulation techniques are: unipolar modulation of the upper transistors (PWM-TOP) and bottom transistors (PWM-BOT), symmetrical PWM-PWM, modulation type PWM-ON and ON-PWM, and bipolar PWM-ON modulation indicated with PWM-ON-BIP. The voltage source inverter is considered as DC-DC buck power converter, when BLDC is operated in motor mode. On the basis of summarized equivalent circuits, the analytical expressions are received for the electromagnetic processes in the system by the different modulation techniques. The efficiency of the system battery-inverter-machine for each discussed modulation is experimentally investigated and compared. These results are also compared with the efficiency of the BLDC driven with vector control. A MATLAB/SIMULINK model is proposed to implement these modulations and to analyze the obtained results. From this model, the harmonic composition of the phase currents for each modulation is investigated.
\end{abstract}

Keywords BLDC Motor, Modulations, DC-DC Power Converter

\section{Introduction}

The main energy consumer in electric vehicles is the propulsive electric machine. It is therefore important that this machine is energy efficient and that its management methods result in less energy loss [1,2]. Of particular importance is the ability of the machine to operate in generator mode to recover energy in the rechargeable batteries or in the supercapacitor unit during deceleration
$[7,8]$.

BLDCs are widely used in electric vehicle systems. The presence of an inverter in these systems and proper control can enable the generation mode of operation of the brushless DC machine, which is essential for electric vehicles. For this purpose, the inverter can operate as a bidirectional DC-DC converter.

In the process of analysis, the literature mainly discusses the influence of the methods for modulating the voltage applied to the machine coils on the torque. A discussion, however, is not presented on the extent with which each of these methods affects the efficiency of control and energy loss in the brushless machine [4-8]. This is extremely important in the case when a brushless machine is used in an electric vehicle, where the aim is to accomplish high efficiency and lower energy consumption.

In $[1,4]$, a mathematical description is proposed of the electromagnetic processes in a brushless machine after applying a supply voltage. No consideration, however, is given to the exchange of energy with the power source and the processes in the system power supply - converter BLDC using different types of modulation. Paper [9] discusses the electromagnetic processes in the exchange of energy between the electrical machine and the power source while operating the machine in generator mode using different types of modulations.

The purpose of this paper is to investigate the processes of energy exchange between the electrical machine and the power source when the machine operates in motor mode using different modulation techniques. The voltage source inverter is considered as DC-DC power converter.

\section{Analyses of the Modulation Techniques to Control BLDC Motors}

The circuit of a three-phase voltage inverter supplying a 
3-phase BLDC motor is shown in Fig. 1. For the control of 3-phase BLDC motors, a six-step switching algorithm is used. Each step corresponds to a specific state of the transistors of the three-phase inverter for $60^{\circ}$. There are several basic types of modulations for controlling brushless machines.

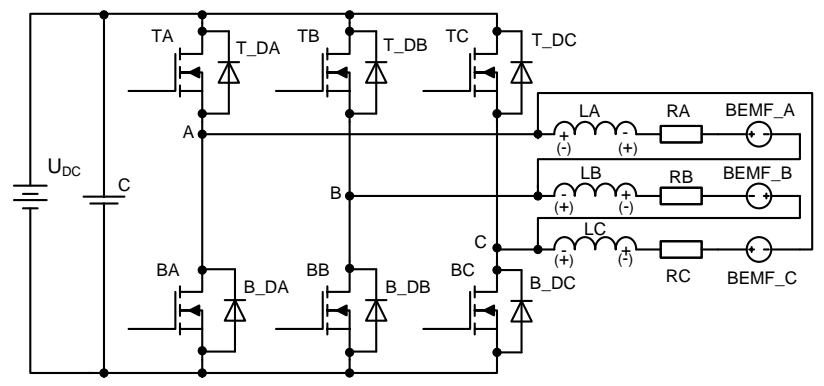

Figure 1. Schematic diagram of the electric drive system

Waveforms of the studied modulation techniques are shown in Fig. 2 - Fig. 4.

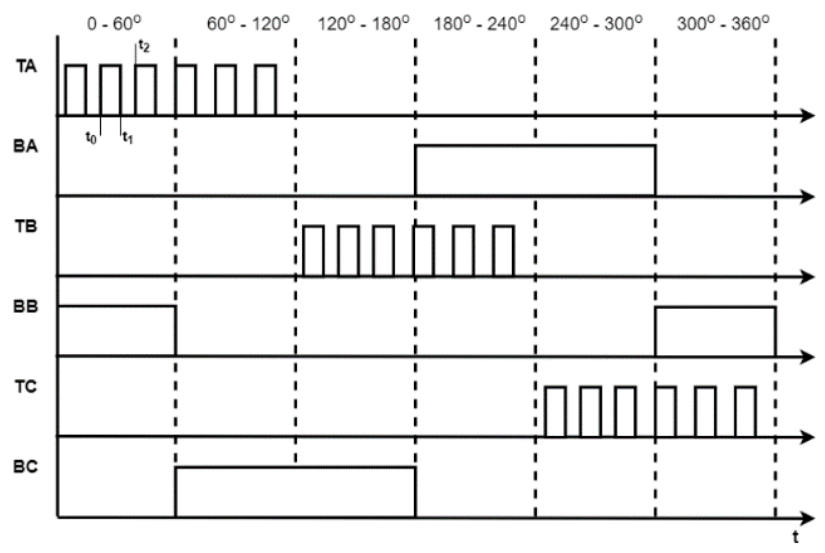

Figure 2. Unipolar modulation of upper transistors: PWM-TOP

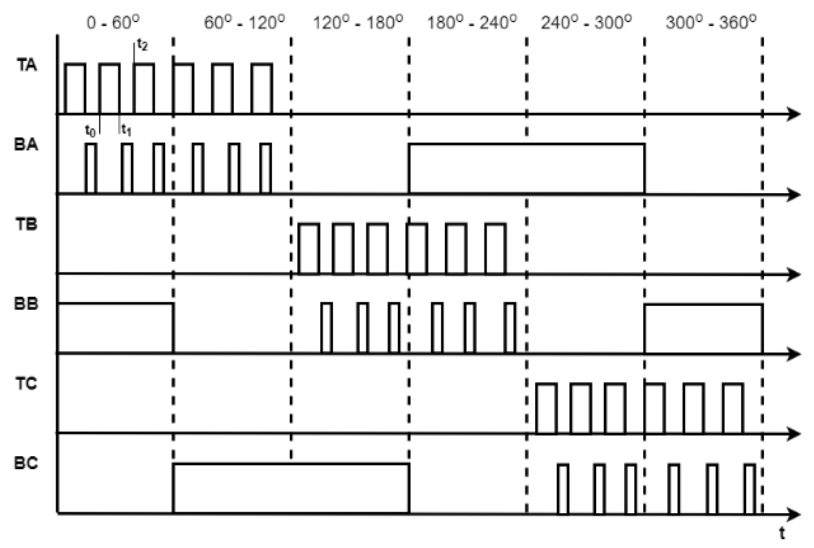

Figure 3. PWM-PWM modulation

Investigated are: unipolar modulation of the upper transistors (Fig. 2) PWM-TOP and bottom transistors PWM-BOT, symmetrical PWM-PWM (Fig. 3), modulation type PWM-ON and ON-PWM, and bipolar PWM-ON modulation indicated with PWM-ON-BIP in the text (Fig. 4). In unipolar modulation of lower transistors PWM-BOT, unlike PWM-TOP, transistors BA, BB and $\mathrm{BC}$ are modulated. The control signals for the ON-PWM and PWM-ON modulations lack the complementary operation of two transistors on the same inverter leg, such as the PWM-ON-BIP modulation.

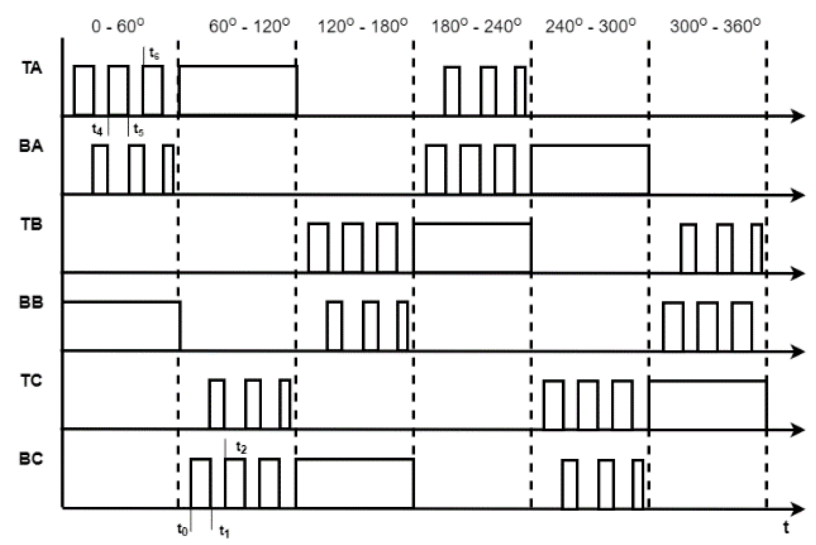

Figure 4. PWM-ON-BIP modulation

The electromagnetic processes in the system power source-converter-brushless machine are examined by monitoring the direction of the current for each step of the six-step switching algorithm. For these 60 electric degrees, the opposite is assumed that the back emf of the conducting phases has a constant value.

Analyses of electromagnetic processes in the system inverter-machine and the rechargeable battery in literature are predominantly for BLDC machines in a Y connection of the phase coils. These are also the most common in the field as opposed to $\Delta$-connection. This is due to the increased energy losses in the circuit of the third harmonic of the trapezoidal voltage, which has amplitude of approximately $22 \%$ of the first harmonic [1].

This results in the limited use of brushless DC motors in the $\Delta$ connection for high power applications, and is more commonly used for low power and light electric vehicles [1,2] but represents a field for additional research and analysis of the electromagnetic processes with the goal to increase efficiency.

By applying PWM-TOP modulation in the voltage inverter (Figure 2), for a period of $60^{\circ}$, the upper transistor from one leg of the inverter and the lower transistor from the other leg work together. A PWM signal with duty cycle $\mathrm{D}$ is applied to the upper transistor. The lower transistor is completely switched on for the entire duration. An interval is considered in which the phase B lower transistor BB is completely switched on and the phase A upper transistor TA is modulating. Fig. 1 shows the polarity of the energy in the inductances LA, LB, and LC of the phase windings and the polarities of the back-EMF for each phase BEMF_A, BEMF_B, and BEMF_C when transistor TA and transistor $B B$ are on for time interval $t_{0}$ to $t_{1}$. Current flows in a circuit composed of $+\mathrm{U}_{\mathrm{DC}}-\mathrm{TA}$ - phase $\mathrm{A}$ and the phases 
connected in series B and C - BB - - UDC. During this conduction interval, energy is accumulated in the phase inductances LA, LB and LC, with the polarity as shown in the Figure 1 without the brackets.

In the next interval $t_{1}$ to $t_{2}$ transistor TA is switched off and $\mathrm{BB}$ remains switched on. As a result of the exclusion of TA, the polarity of the energy accumulated in the phase inductors is reversed and becomes the signs indicated in Figure 1 with the brackets. With enough energy accumulated, the diode B_DA turns on. Current flows in the circuit consisting of B_DA - phase A and the phases connected in series B and C - BB. The energy accumulated in the inductances LA, LB and LC is dissipated through the inverter.

Fig. 5A shows the three windings $\mathrm{A}, \mathrm{B}$ and $\mathrm{C}$ with their own inductance $\mathrm{LA}, \mathrm{LB}$ and $\mathrm{LC}$, active resistance RA, RB and RC, and equivalent back emf BEMF_A, BEMF_B and BEMF_C. It is assumed that the windings are the same and the inductance values are equal to $L_{p h}$, the active resistance of each winding is equal to $R_{p h}$.

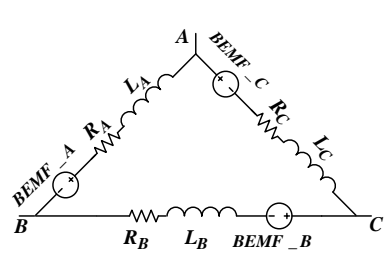

A

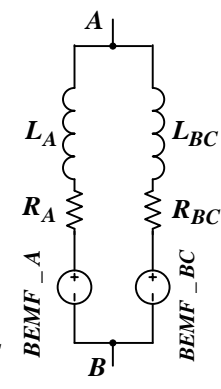

B

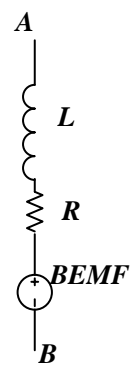

C
Figure 5. Transformation of three phase windings in $\Delta$ connection into one equivalent phase winding

For the impedance of the parallel connected branches $Z_{e q}$ (when converting the scheme into one branch Fig.5C), we obtain:

$$
Z_{e q}=R+j X
$$

where $R$ and $X$ are equal to:

$$
\begin{gathered}
R=\frac{6 X_{p h}^{2} X_{p h}+6 R_{p h}^{3}}{9\left(R_{p h}^{2}+X_{p h}^{2}\right)}=\frac{2}{3} R_{p h} \\
X=\frac{6 R_{p h}^{2} X_{p h}+6 X_{p h}^{3}}{9\left(R_{p h}^{2}+X_{p h}^{2}\right)}=\frac{2}{3} X_{p h} \Rightarrow L=\frac{2}{3} L_{p h}
\end{gathered}
$$

The next step is to find the voltage value $\mathrm{U}_{\mathrm{BEMF}}$

$$
U_{B E M F}=Z_{\text {eкв }} \sum_{k=1}^{n} \frac{U_{B E M F}}{Z_{k}}=\frac{2 U_{B E M F_{-} A}+U_{B E M F_{-} B C}}{3}
$$

\section{Analysis of Electromagnetic Processes in the Inverter-Machine-Battery System for Motor Operation of the BLDC Machine}

\subsection{Modulation of Upper Transistors - PWM-TOP}

For the PWM-TOP modulation in Figure 6 summarized equivalent circuit is presented for the two intervals corresponding to when the top transistor of the leg A (TA) has PWM signal on it and the diode B_DA which is switched on due to the energy accumulated in the windings when the transistor is off. The BLDC motor is represented by the equivalent circuit in Fig. 5C.

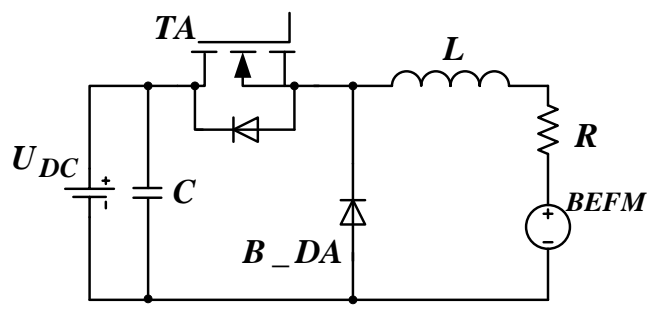

Figure 6. Summarized equivalent circuit for PWM-TOP modulation

Thus, the inverter is reduced to a step-down converter for which the load is the active resistance $\mathrm{R}$ and the back-EMF.

In order to analyze the electromagnetic processes in the inverter-machine-battery system for the motor mode of operation of the BLDC machine, principles used in the analysis of DC-DC converters are used. As a result, the following can be written for the motor mode of operation with modulation of the upper transistors for the average values of the voltage across the inductance $\mathrm{U}_{\mathrm{L}}$ and the current through the capacitor $\mathrm{I}_{\mathrm{C}}$ :

$$
\begin{aligned}
& \int_{t}^{t+T_{S}} u_{L_{A}}(t) d t=D T_{S}\left(U_{D C}-i_{L} R-i_{L} R_{D S_{O n}}-U_{B E M F}\right)+ \\
& +D^{\prime} T_{S}\left(-U_{B E M F}-i_{L} R-U_{D}\right)=0
\end{aligned}
$$

$$
\int_{t}^{t+T_{S}} i_{C}(t) d t=D T_{S}\left(\frac{U_{D C}}{R_{b}}-i_{L}\right)+D^{\prime} T_{S}\left(\frac{U_{D C}}{R_{b}}\right)=0
$$

where: $T_{S}$ is the switching period, $U_{B E M F}$ is the voltage of the equivalent voltage source, $i_{L}$ is the current through the inductor, $R$ is the active resistance, $R_{D S o n}$ is the resistance of the channel of the MOSFET transistor, $U_{D}$ is the voltage drop across the diode, $U_{D C}$ is the voltage of the battery, $R_{b}$ is the internal resistance of the battery and $D$ is the duty cycle $\left(D=t_{O n} / T_{S}\right)$. The 
relationship between $D$ and $D^{\prime}$ is: $D^{\prime}=1-D$. Using this connection and solving (6) with respect to the current through the inductance $i_{L}$, we obtain:

$$
i_{L}=\frac{U_{D C}}{R_{b}}
$$

Replacing (7) in (5), the voltage of the equivalent voltage source is obtained:

$$
U_{B E M F}=U_{D C}(D-D \cdot Z-K)+U_{D}(D-1)
$$

where: $K=R / R_{b}$ [4] and $Z=R_{D S o n} / R_{b}$. Due to the fact that the two resistances differ in order, in further analysis $\mathrm{Z}$ can be neglected.

Equation (8) shows that the connection between the supply voltage $U_{D C}$ and the output voltage $U_{B E M F}$ is similar to that of a step-down converter and is proportional to the duty cycle $D$.

Given these assumptions, (8) takes the following form:

$$
U_{B E M F}=U_{D C}(D-K)+U_{D}(D-1)
$$

\subsection{Modulation of Bottom Transistors - PWM-BOT}

A summarized equivalent circuit is illustrated in Figure 7 for the two intervals corresponding to when the bottom transistor is turned on and the diode is switched on:

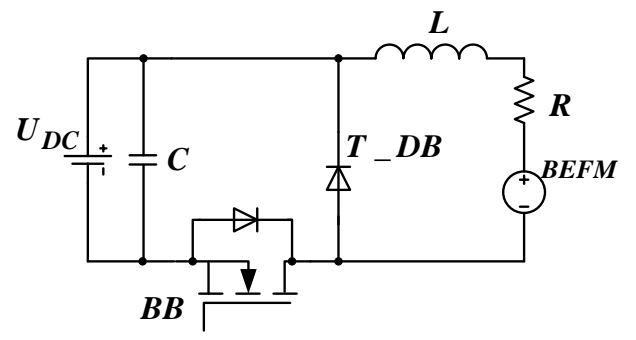

Figure 7. Summarized equivalent circuit for PWM-BOT modulation

It can be seen that, again, the inverter can be considered as a DC-DC buck converter, for which the load is the active resistance $\mathrm{R}$ and the back-EMF. Thus, for a low-transistor modulation mode, the average values of the voltage across the inductance $\mathrm{U}_{\mathrm{L}}$ and the current through the capacitor $\mathrm{I}_{\mathrm{C}}$ can be valid (5) and (6).

For the PWM-ON and ON-PWM modulations, it can be said that the switching sequence of the transistors through 60 electrical degrees leads to an alternation of modulation of the upper and lower transistors. Thus, for each of these intervals, the inverter can again be represented as a DC-DC buck converter.

\subsection{Analysis of the Processes in the System Power Source-Inverter-Motor System Using PWM-PWM Modulation}

The use of PWM-PWM modulation of the inverter transistors (Figure 3) within 60 electrical degrees implies complementary operation of the transistors from one inverter leg, while the lower transistor of the other leg is completely switched on for the entire duration. PWM signals with duty cycle $D$ are transmitted to the upper transistor from inverter leg and to the lower transistor from the same leg-pulses with a duty cycle $D^{\prime}$.

A summarized equivalent circuit for the intervals with the modulating upper transistor switched on and the lower modulating transistor switched on is shown in Figure 8.

For the inductance current (7) is valid and for the back-EMF is obtained:

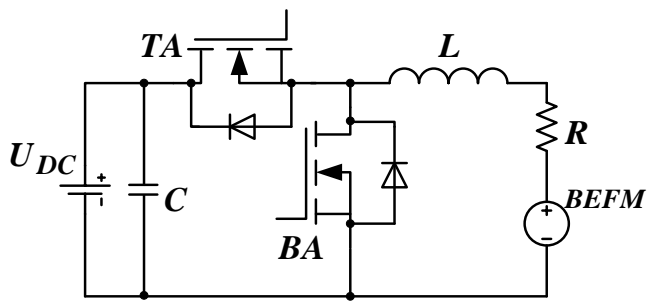

Figure 8. Summarized equivalent circuit for PWM-PWM modulation

$$
U_{B E M F}=U_{D C}(D-K)
$$

In this case, the losses in the DC-DC buck converter decrease compared to the PWM-TOP and PWM-BOT modulations due to the low voltage drop across the MOSFET.

\subsection{Analysis of the Processes in the System Power Source-Inverter-Motor System Using PWM-ON-BIP Modulation}

Two cases can be considered when using PWM-ON-BIP modulation (Figure 4):

Case I: For an interval of $60^{\circ}$, an upper transistor of the inverter leg is switched on and complementary modulation is applied to the transistors of the other leg - for example, transistor TA is completely $\mathrm{ON}$, and TC and $\mathrm{BC}$, switched in a complementary manner with a duty cycle $D$ and $D$ respectively.

The summarized equivalent circuit for the intervals with the modulating lower transistor switched on and the upper modulating transistor switched on is shown in Figure 9.

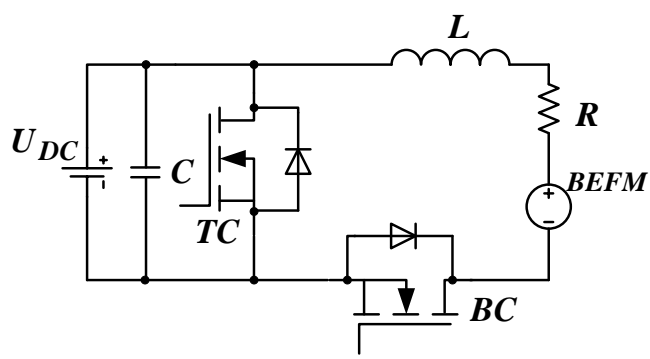

Figure 9. Summarized equivalent circuit for PWM-ON-BIP modulation: Case I 
Case II: For an interval of $60^{\circ}$, a lower transistor from the inverter leg is switched on and complementary modulation is applied to transistors from another leg - for example, transistor BB is completely open and TA and BA operate in a complementary manner with $\mathrm{D}$ and $\mathrm{D}$ 'respectively. The summarized equivalent circuit is the same as the one in Figure 8.

In both cases, mathematical analysis leads to a value of the current equal to (7). The relationship between the output voltage and the power supply is described by (10).

\section{Practical Implementation}

The DRV8312-C2 development system and the brushless motor DT4260-24-055-04, whose parameters are presented in Table 1, are used to study the effect of each of the modulation techniques described.

The DRV8312-C2 development system is based on the TMS320F28035 microprocessor from the Piccolo family and Texas Instruments smart three-phase DRV8312 driver.

Table 1. Parameters of motor DT4260-24-055-04

\begin{tabular}{|c|c|}
\hline Rated Voltage (V) & 24 \\
\hline Rated Power (W) & 55 \\
\hline Rated Speed (rpm) & 4000 \\
\hline Rated Torque (Nm) & 0.125 \\
\hline Back-EMF Voltage (V/kRPM) & 2.7 \\
\hline
\end{tabular}

The described algorithms for switching the transistors of the intelligent three-phase inverter DRV8312 are achieved by sending control signals to the PWM-X and RESET_X inputs from the TMS320F25032 microprocessor. As it was previously outlined, the signals supplied to the PWM-X inputs turn on an upper or lower transistor from a given inverter leg. If these signals are modulated, complementary operation of the transistors on the same leg will be achieved. But in order to repeatedly switch one transistor from the leg and keep the other off, the RESET_X inputs are used.

The modulation techniques described so far are carried out in a similar manner. The following lines provide an example code for generating PWM-ON-BIP modulation for the first step of the 6-step algorithm when current flows from phase A to phase $\mathrm{B}$.

$$
\begin{aligned}
& \text { EPwm1Regs.AQCSFRC.bit.CSFA }=2 ; / / T A-\text { on } \\
& \text { EPwm1Regs.AQCSFRC.bit.CSFB }=2 ; / / \text { Enable } \\
& \text { EPWM1 } \\
& \text { EPwm2Regs.AQCSFRC.bit.CSFA }=0 ; / / \text { Disable A } \\
& \text { channel of EPWM2 } \\
& \text { EPwm2Regs.AQCTLA.bit.CAU }=1 ; / / \text { Set to } 0 \text { when } \\
& \text { CTR }=\text { CMPA } \\
& \text { EPwm2Regs.AQCTLA.bit.ZRO = 2;// Set to } 1 \text { when } \\
& \text { CTR }=0 \\
& \text { EPwm2Regs.CMPA.half.CMPA }
\end{aligned}
$$
(int16)(Tmp >>15);/* Complementary PWM operation of EPWM2

EPwm2Regs.AQCSFRC.bit.CSFB $=2$; // Set to 1 output $B$ of EPWM2

EPwm3Regs.AQCSFRC.bit.CSFA = 1; //Set to 0 output A of EPWM3

EPwm3Regs.AQCSFRC.bit.CSFB = 1;// Set to 0 output $B$ of $E P W M 3 /$

The other five steps of the algorithm are similar to the first step, except that at times when the upper and lower transistors have a duty cycle with respect to the first step.
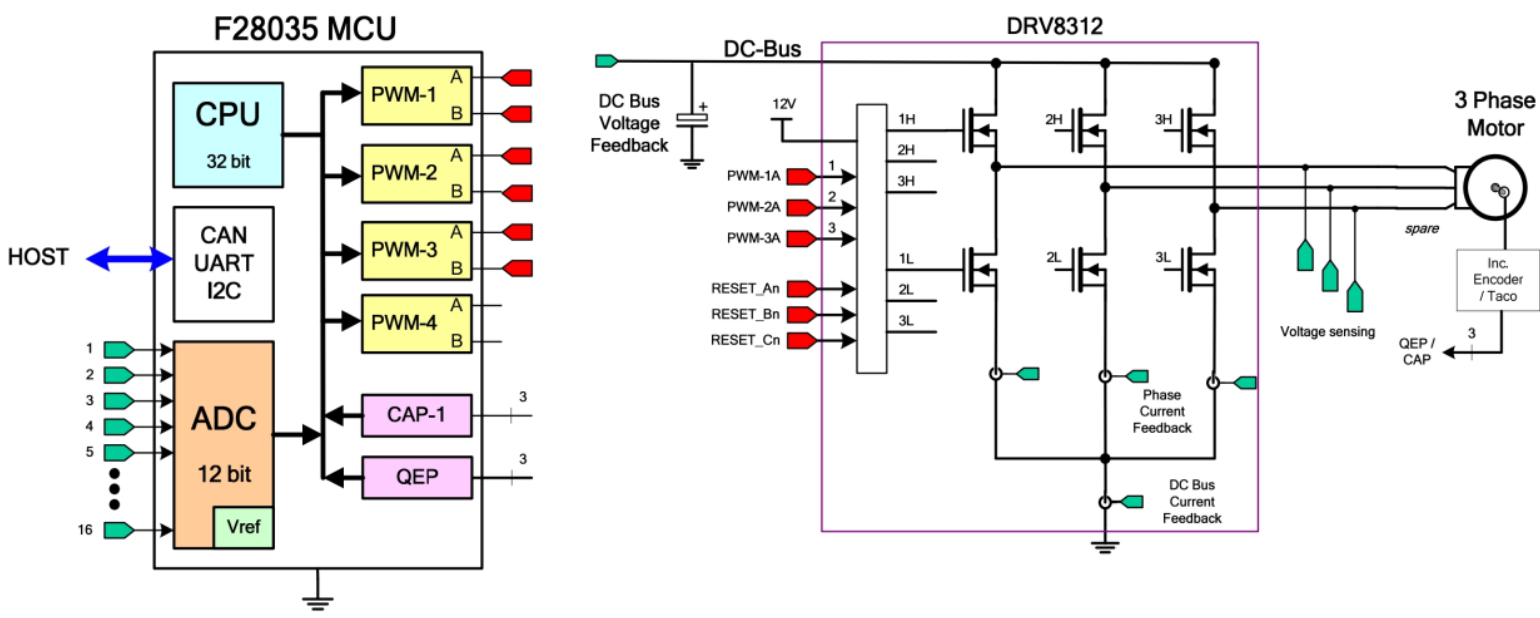

Figure 10. Block diagram of development system 
Figure 11 shows the control signals applied to DRV8312 driver to accomplish the unipolar PWM-TOP modulation on the inverter leg $\mathrm{A}$.

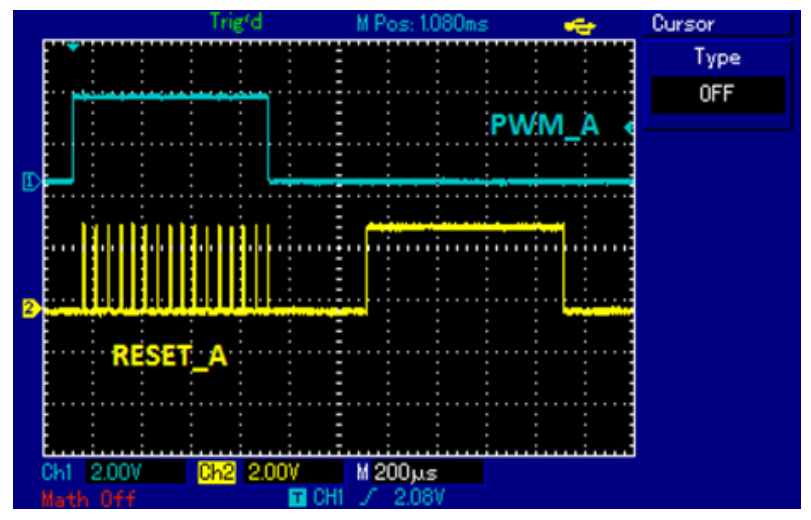

Figure 11. Control signals for unipolar PWM-TOP modulation

Figure 12 shows the same signals for symmetrical PWM-PWM modulation. Figure 13 shows the signals for bipolar PWM-ON-BIP modulation. The pulse width modulation frequency $\mathrm{f}_{\mathrm{m}}$ is set to $12 \mathrm{kHz}$.

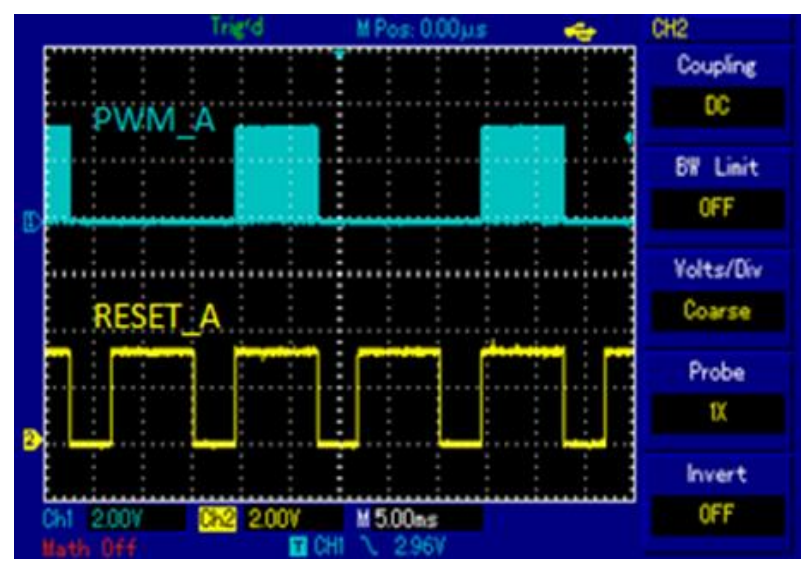

Figure 12. Control signals for PWM-PWM modulation

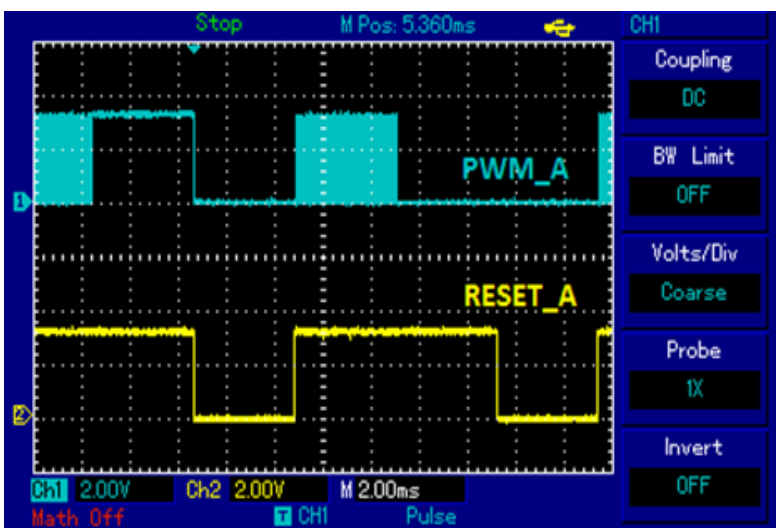

Figure 13. Control signals for PWM-ON-BIP modulation

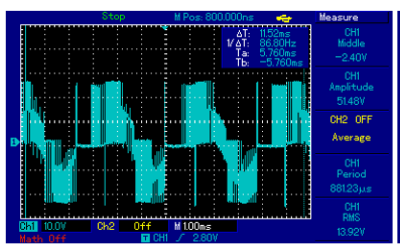

a)

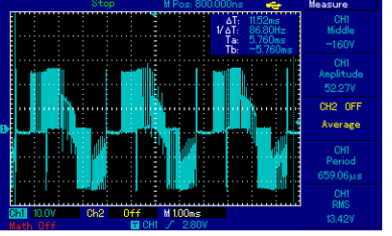

b)

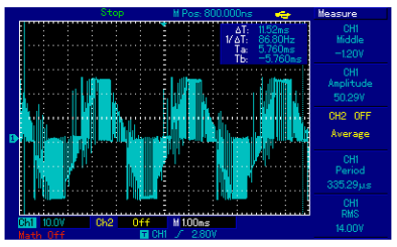

c)

Figure 14. Line-to-line voltages between phase A and phase B for different types of modulations: a) unipolar modulation; b) symmetric PWM-PWM modulation; c) bipolar PWM-ON-BIP modulation

Waveforms of the line-to-line voltage measured between phase A and phase B are presented in Figure 14 for three of the tested modulations.

Taking into account the electric power $P$ consumed by the brushless machine and calculating the mechanical power $\mathrm{P}_{\mathrm{M}}$ generated by the (11), the efficiency of the machine is calculated by (12)

$$
P_{M}=M \cdot \omega
$$

Where $\mathrm{M}$ is the output torque in $\mathrm{Nm}$ and $\omega$ is the motor speed in $\mathrm{rad} / \mathrm{s}$.

$$
\eta=P_{M} / P
$$

A comparison is made in Figure 15 of the efficiency $\eta$ of the machine with the considered modulations and referent vector control for nominal power of $55 \mathrm{~W}$ at a nominal speed of $4000 \mathrm{rpm}$.

A comparison is made in Figure 15 of the efficiency $\eta$ of the machine with the considered modulations and referent vector control for nominal power of $55 \mathrm{~W}$ at a nominal speed of $4000 \mathrm{rpm}$.

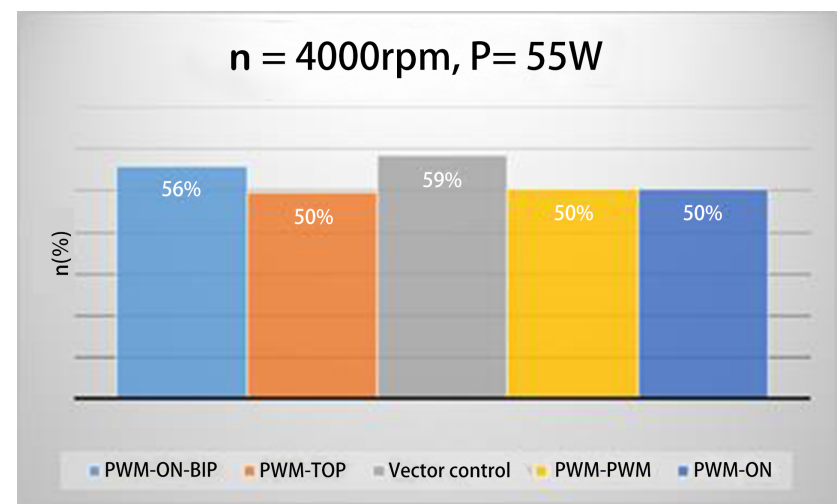

Figure 15. Comparison of the efficiency using different modulations 
For a rated speed of 4000rpm and rated power, the efficiency of the control system and the brushless motor using PWM-TOP, PWM-PWM and PWM-ON is the same, reaching $50 \%$. Using vector control, the system shows the best efficiency, reaching a value of $59 \%$. The efficiency of the system using PWM-ON-BIP modulation is 56\%.

\section{Matlab/Simulink Implementation of PWM-PWM and PWM-ON-BIP Modulations}

\subsection{MATLAB/SIMULINK Model}

In order to analyze the harmonic composition (Fourier analysis) of the motor phase currents for each modulation technique, a model of the electric drive system is implemented in the MATLAB/SIMULINK software. The simulated circuit is shown in Figure 16. The voltage source $\mathrm{V}_{\mathrm{dc}}$ supplies $\left(\mathrm{V}_{\mathrm{dc}}=24.85 \mathrm{~V}\right)$ a three-phase voltage source inverter [10]. The input voltage, the input current and power are measured. The three terminals for the inverter phase voltages are connected to the corresponding inputs of a model of a BLDC motor. The load resistance moment is set at the input $\mathrm{T}_{\mathrm{m}}$ of the BLDC block. The output $m$ is a vector of measured output signals. In this case, the motor speed, electromagnetic torque, stator current of phase A and the linear voltage between phases $\mathrm{A}$ and $\mathrm{B}$ are measured.

The output $m$ also provides information on the rotor position by means of the $h \_a, h \_b$ and $h \_c$ signals. These signals arrive at the Decoder rotor position block. The output obtained from the decoder block is given as input to the gate triggering block Gates. The second input of the block Gates is also fed the difference between the set speed of the motor RPM and the measured one N (rpm).

The internal structure of the Gates block is shown in Figure 17. It contains a PI controller, which, depending on the difference between the set speed and the one developed by the motor, puts a signal to the PWM generator. Using the logic multiplication blocks and the signals TA, TB, TC, $\mathrm{BA}, \mathrm{BB}$, and $\mathrm{BC}$, unipolar modulation of the upper transistors is accomplished. The received control pulses are fed to the output Gates via the MUX3 multiplexer. The blocks PWM-ON-BIP generator and PWM-PWM generator are used to generate the required series of control signals for the corresponding modulations. When PWM-ON-BIP or PWM-PWM modulation is required, the MUX3 multiplexer blocks are connected to the corresponding outputs of the block receiving the necessary modulation.

Figure 18 presents the internal structures of the generators of the control pulses for PWM-ON-BIP modulation and Figure 19 for PWM-PWM modulation. In control pulse generation circuits for PWM-PWM and PWM-ON-BIP modulations, the main blocks are the state machines for the correct gate triggering control signals. The respective state machines are shown in Figure 20a for PWM-PWM modulation and in Figure $20 \mathrm{~b}$ for PWM-ON-BIP modulation. 


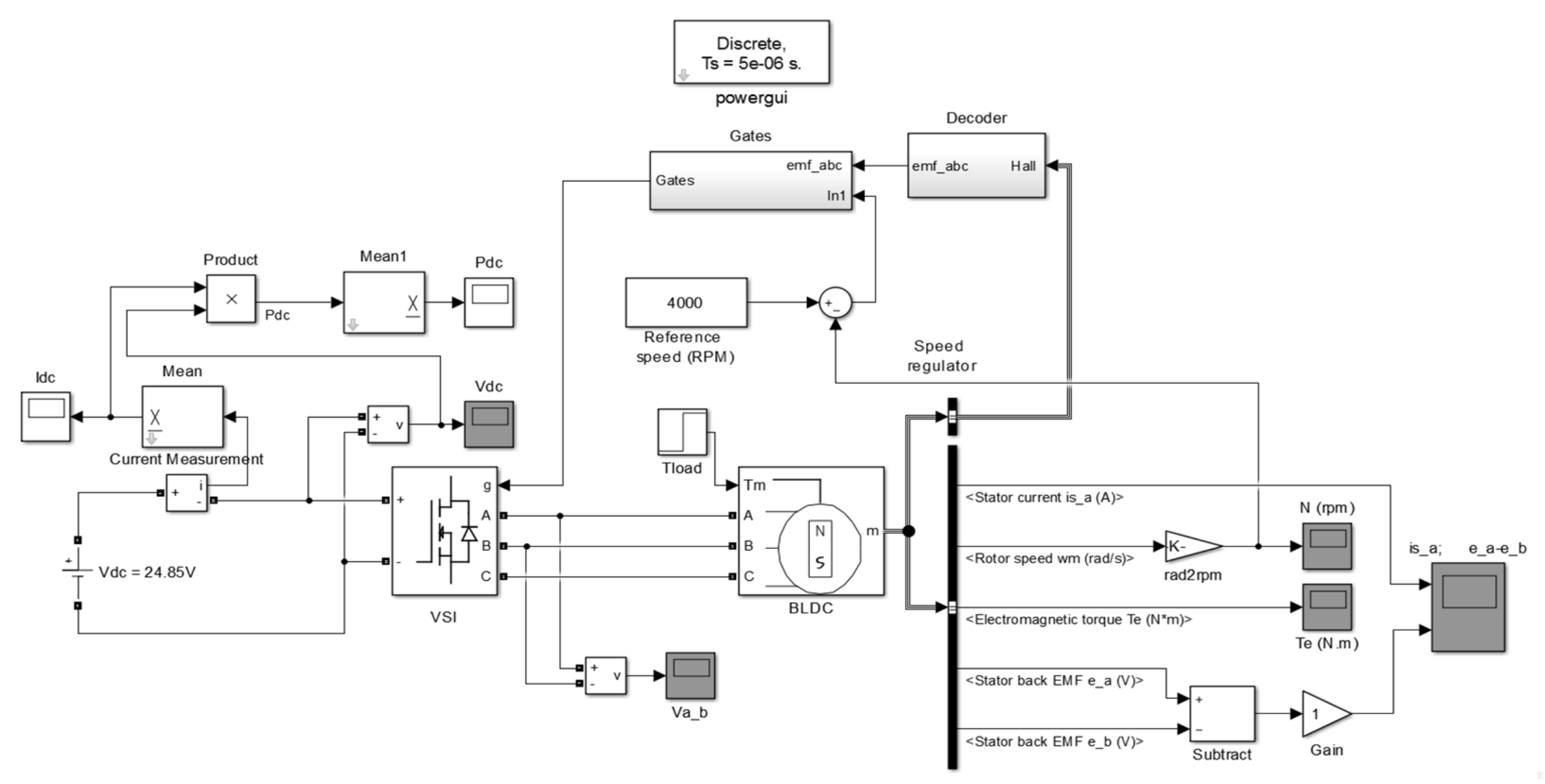

Figure 16. Matlab/Simulink simulation model 


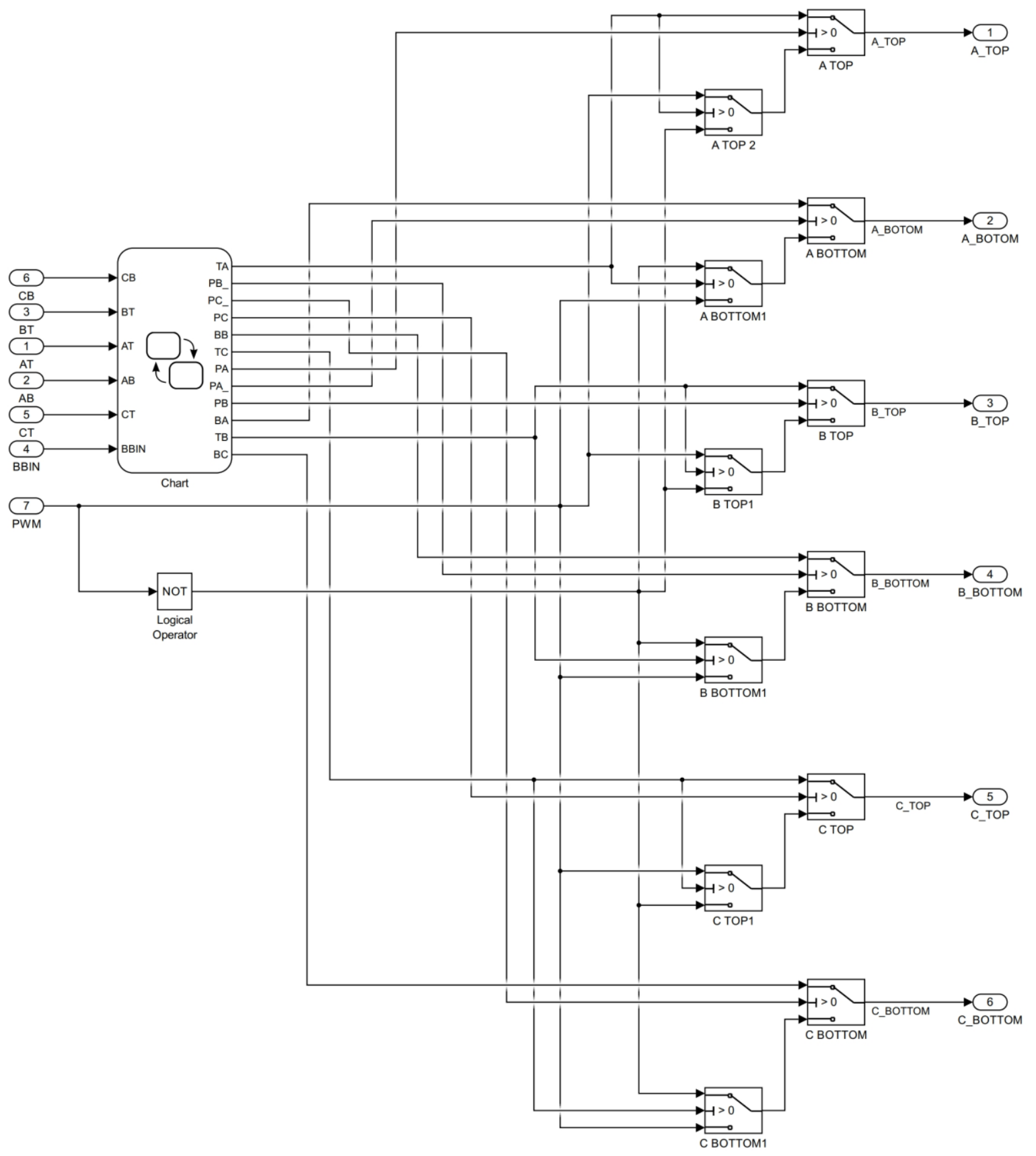

Figure 17. Internal structure of the Gates block 


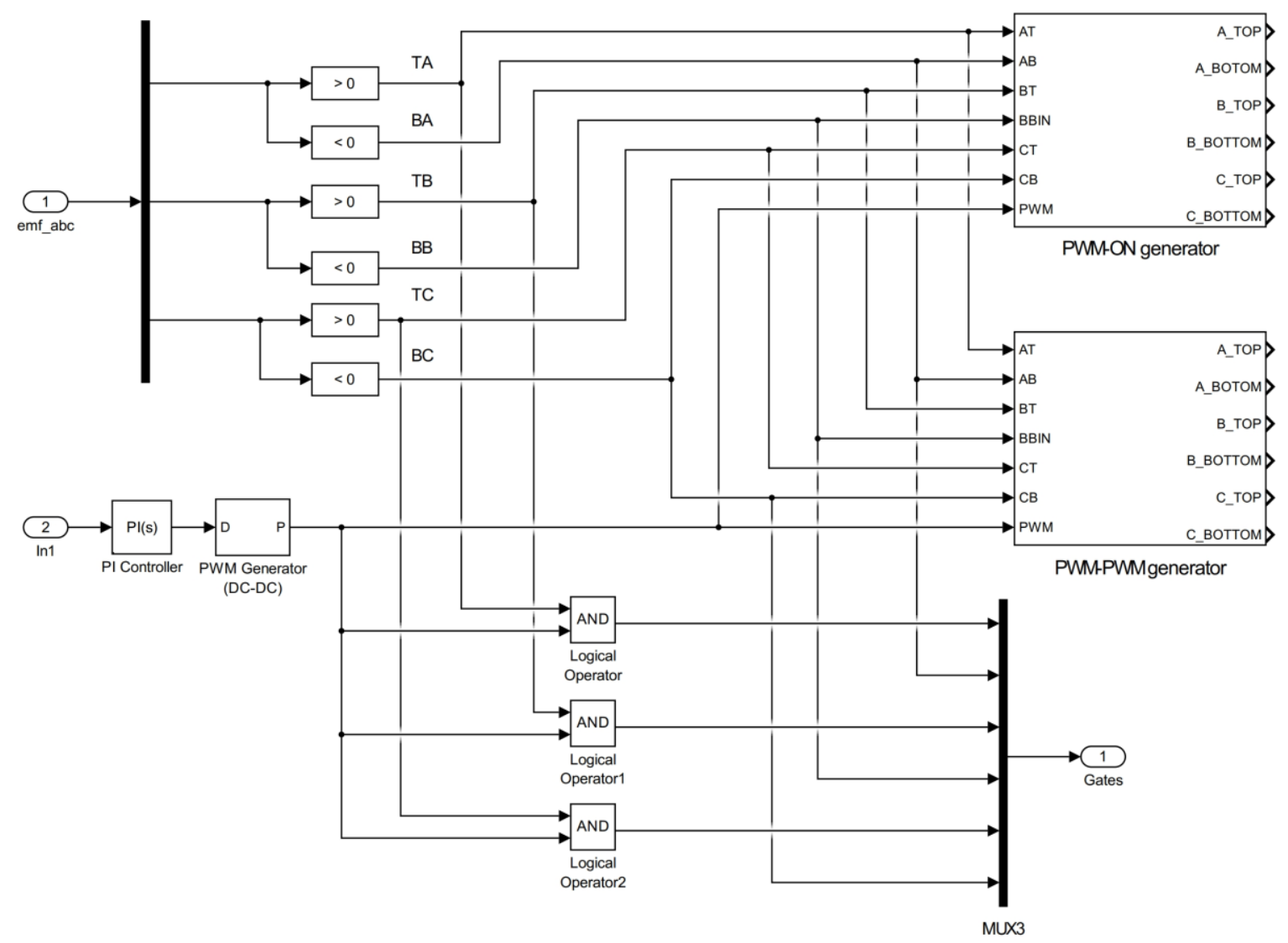

Figure 18. Internal structures of generators of the control pulses for PWM-ON-BIP modulation 


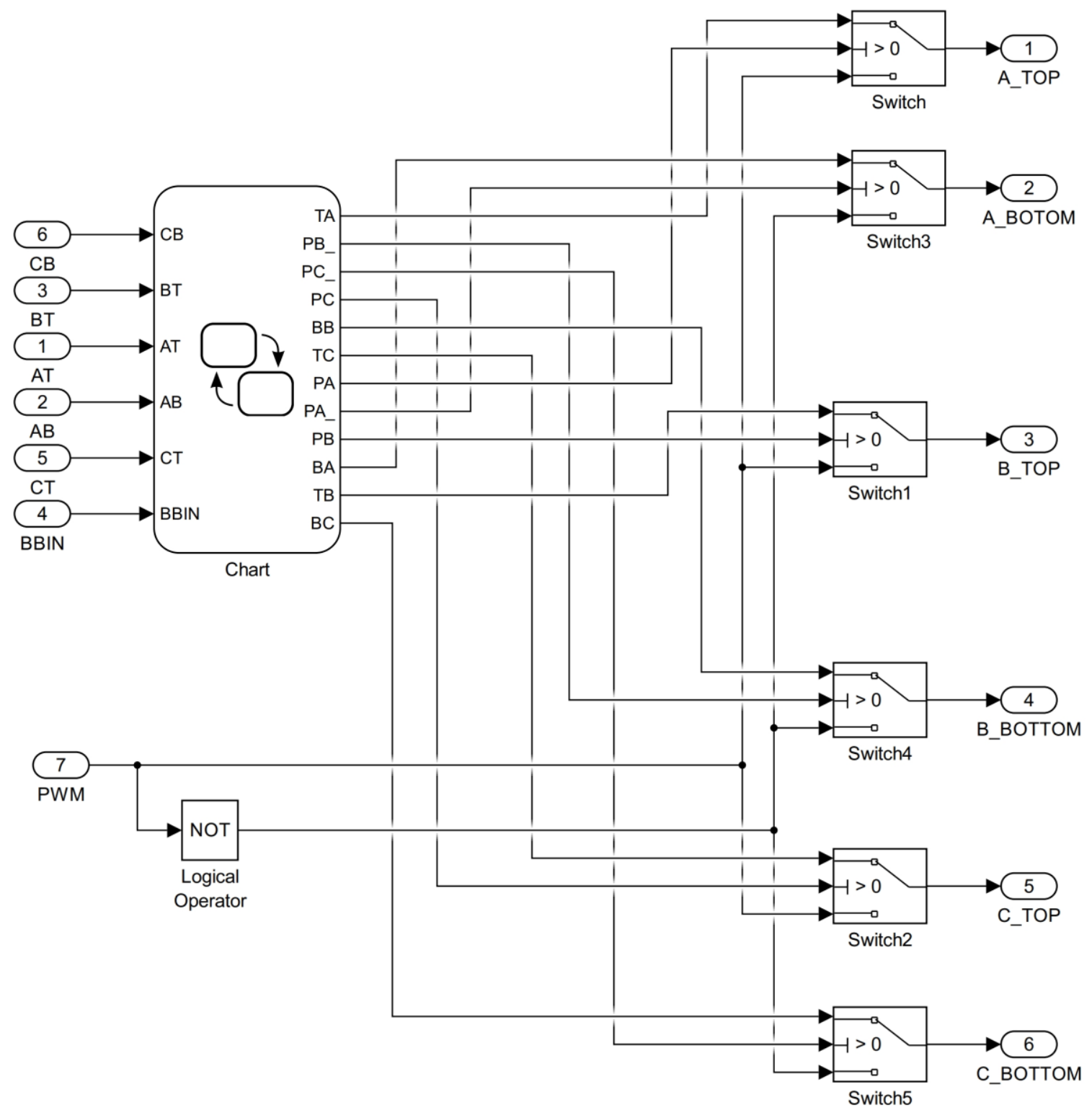

Figure 19. Internal structures of generators of the control pulses for PWM-PWM modulation 


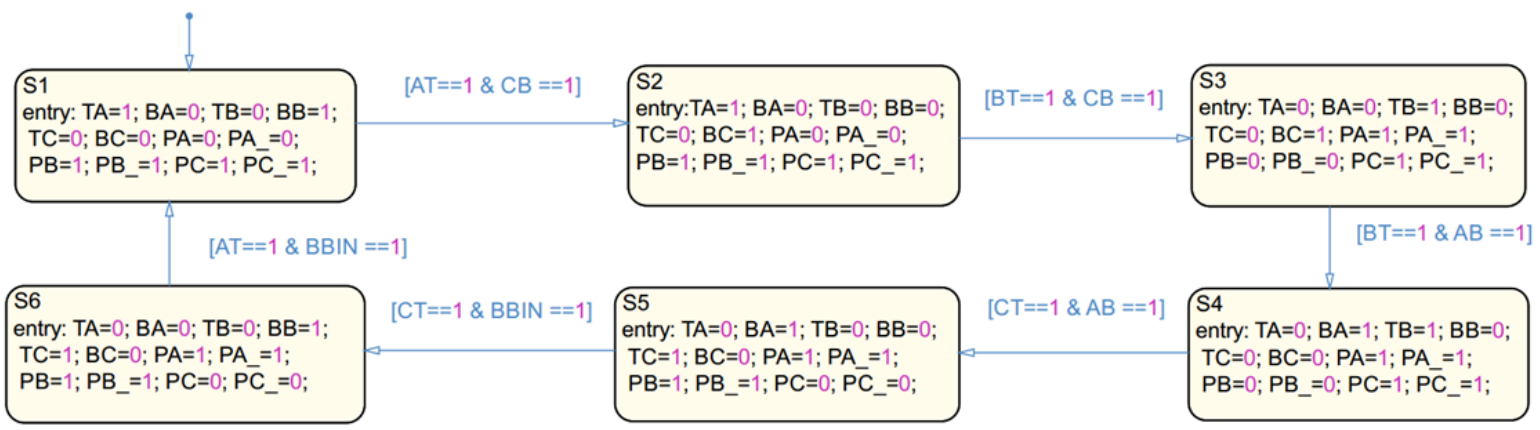

PWM-PWM

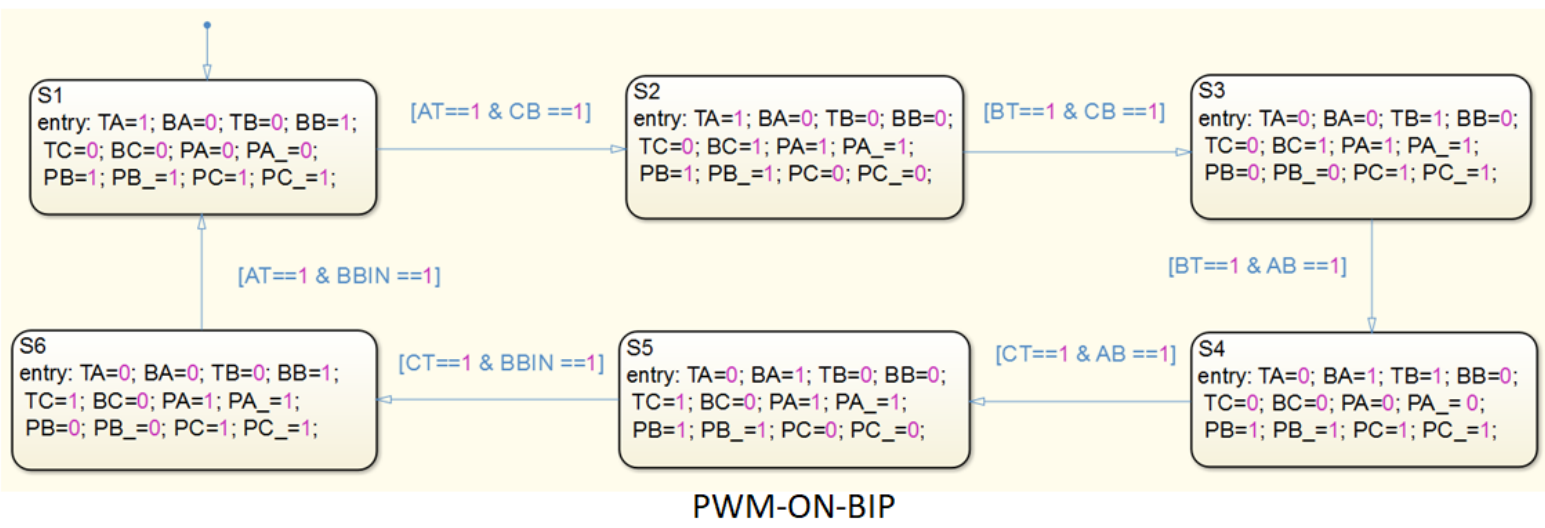

Figure 20. a) State machine for PWM-PWM modulation; b) State machine for PWM-ON-BIP modulation

\subsection{Simulation and Experimental Results}

The MATLAB/SIMULINK results of the motor phase currents for each modulation technique are presented in this paragraph, as well as some experimental waveforms of the phase current. Speed is set at $4000 \mathrm{rpm}$ and the load Torque varies from $0 \mathrm{Nm}$ to $0.076 \mathrm{Nm}$. Under these conditions, for the non-modulating mode with a change in the supply voltage, a Fourier analysis of phase current $\mathrm{I}_{\mathrm{a}}$ is obtained. Fourier analysis of phase current $\mathrm{I}_{\mathrm{a}}$ is obtained also for PWM-TOP, PWM-PWM and PWM-ON-BIP modulations.

Figure 21 and Figure 22 show time-domain representation and frequency-domain representation of a phase current for the PWM-TOP modulation at no-load and $\mathrm{T}_{\text {load }}=0.076 \mathrm{Nm}$, respectively. 

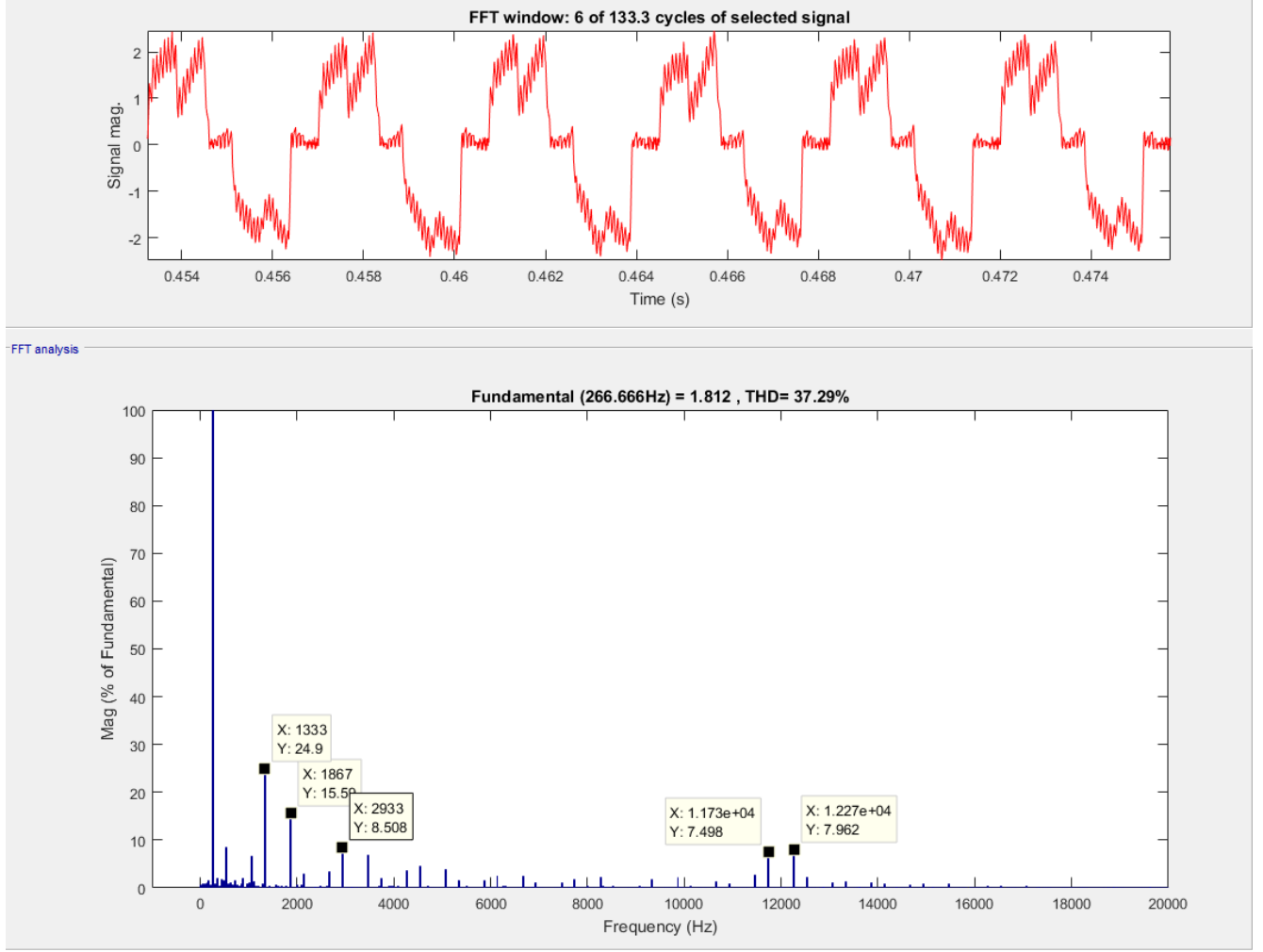

Figure 21. Time-domain representation and frequency-domain representation of a phase current for PWM-TOP modulation at no-load

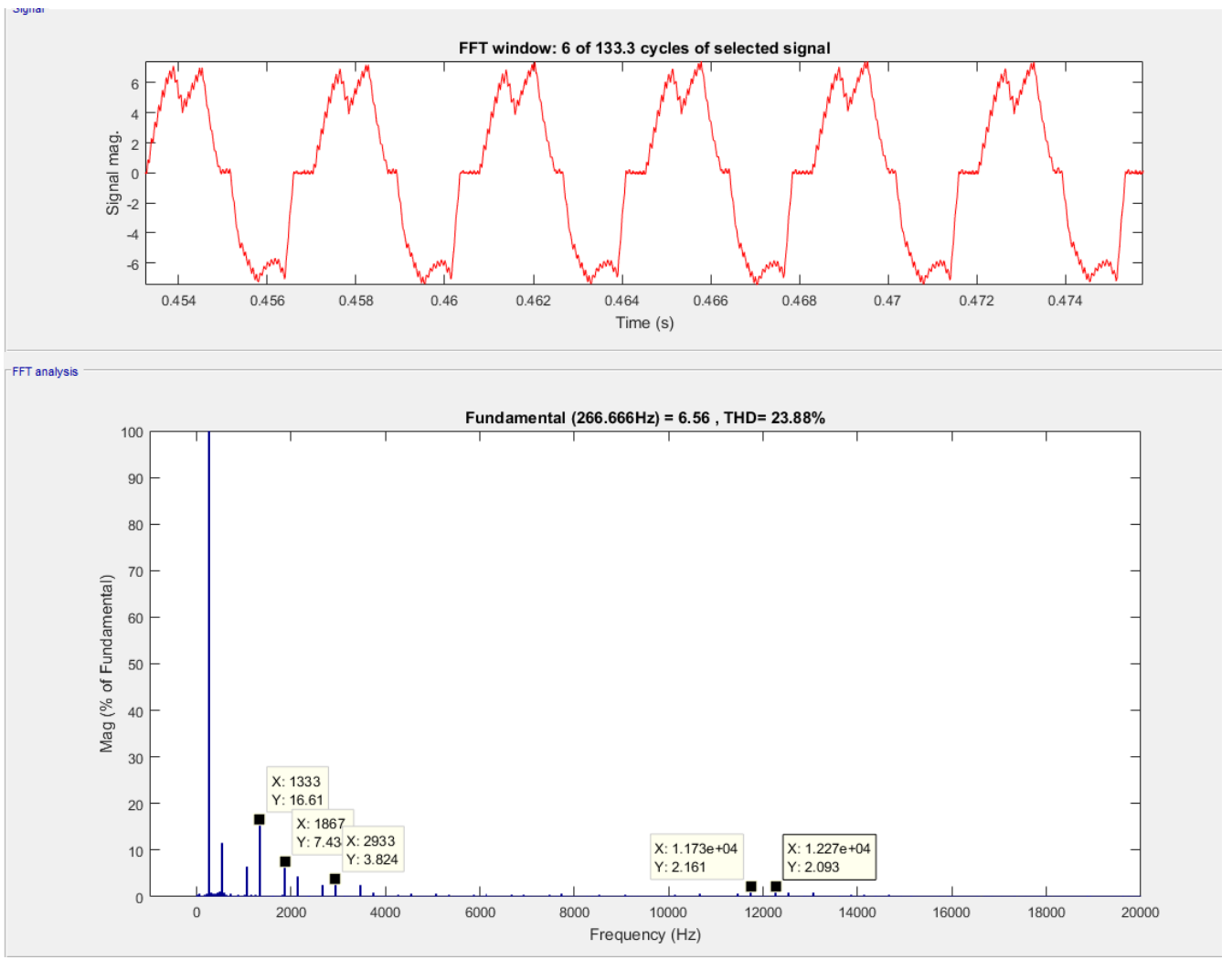

Figure 22. Time-domain representation and frequency-domain representation of a phase current for PWM-TOP modulation at $\mathrm{T}_{\mathrm{load}}=0.076 \mathrm{Nm}$

Figure 23 and Figure 24 show time-domain representation and frequency-domain representation of a phase current for the PWM-PWM modulation at no-load and $\mathrm{T}_{\text {load }}=0.076 \mathrm{Nm}$, respectively. 

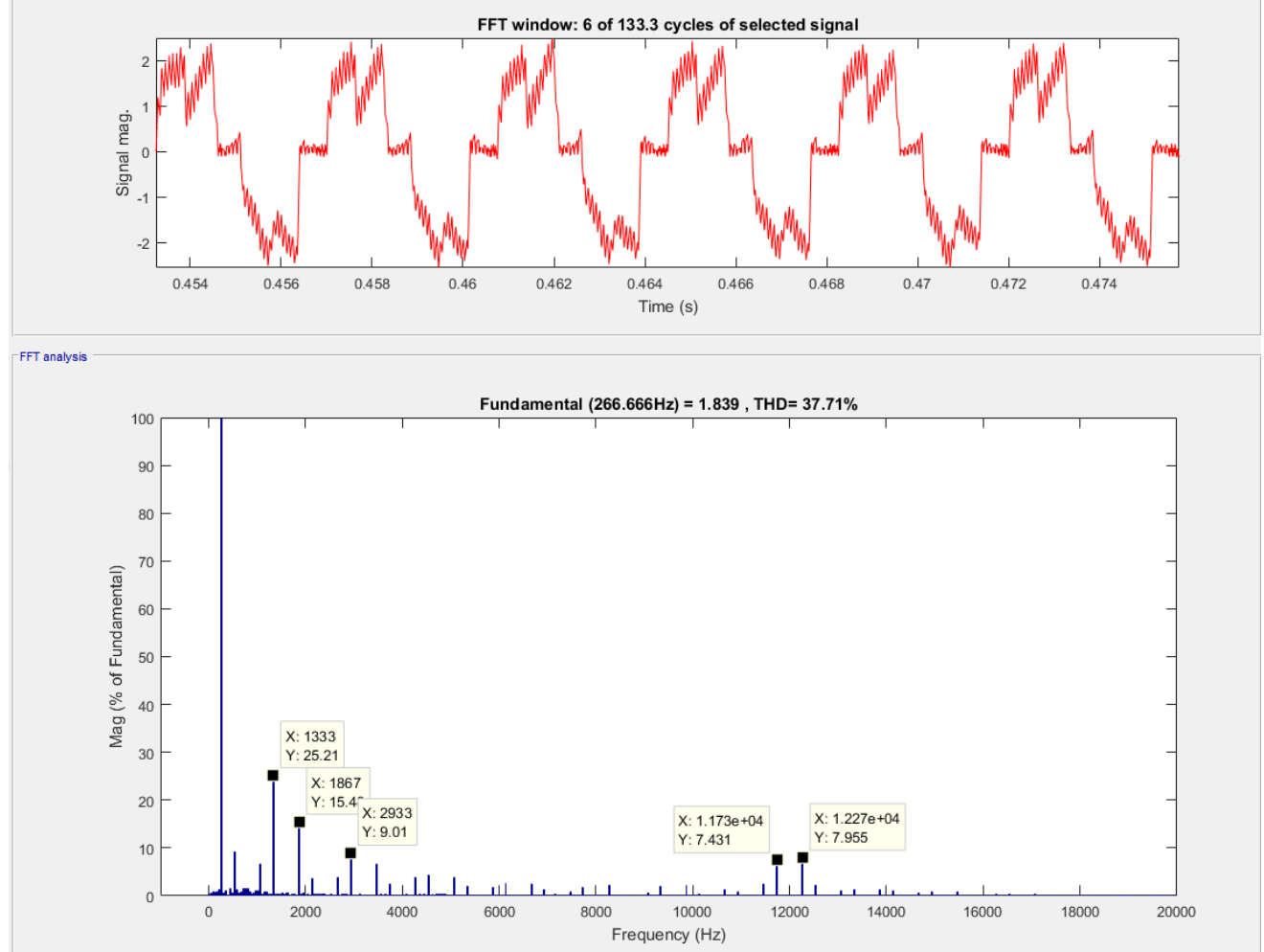

Figure 23. Time-domain representation and frequency-domain representation of a phase current for the PWM-PWM modulation at no-load

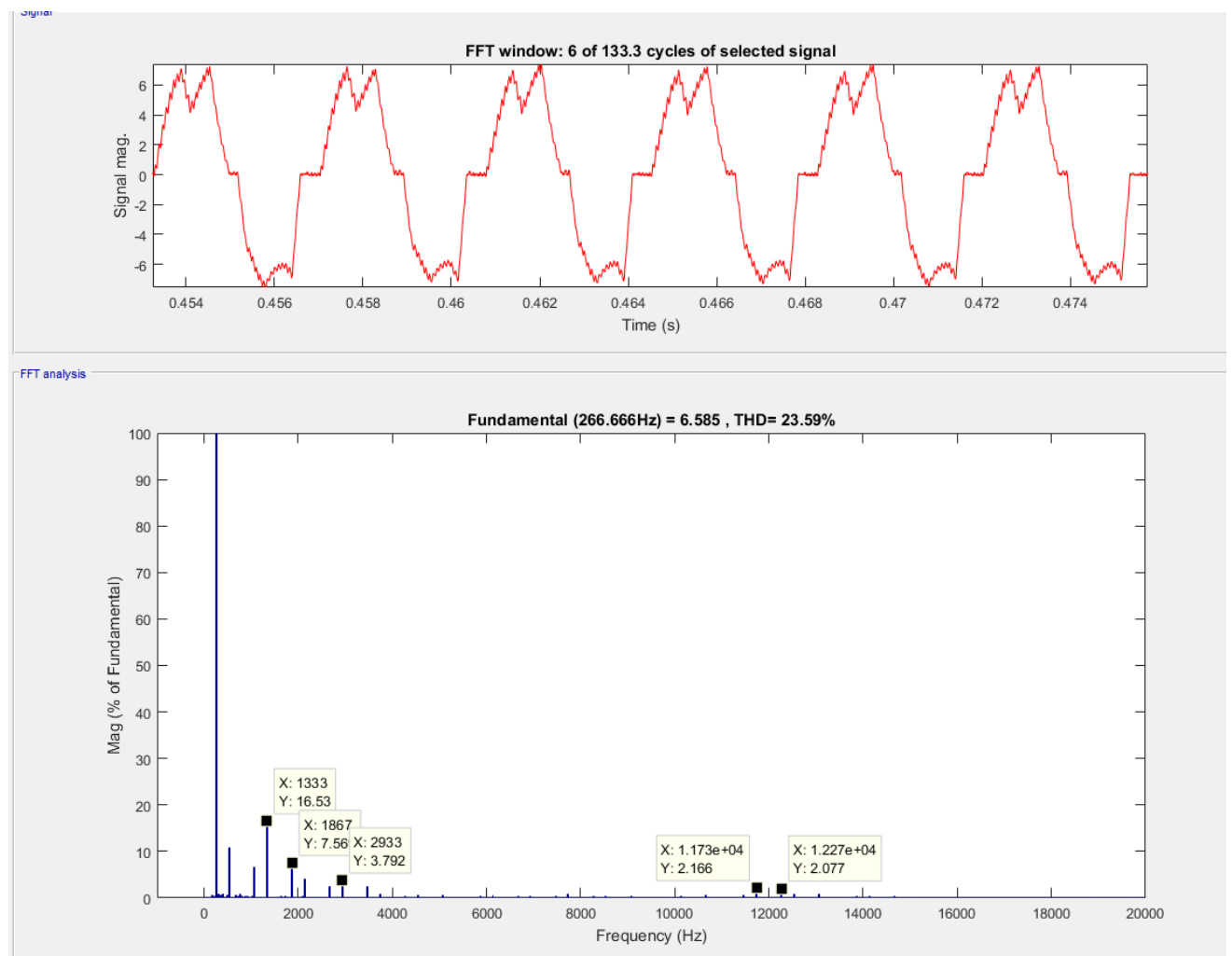

Figure 24. Time-domain representation and frequency-domain representation of a phase current for the PWM-PWM modulation at $\mathrm{T}_{\text {load }}=0.076 \mathrm{Nm}$

Figure 25 and Figure 26 show time-domain representation and frequency-domain representation of a phase current for the PWM-ON-BIP modulation at no-load and $\mathrm{T}_{\text {load }}=0.076 \mathrm{Nm}$, respectively. 

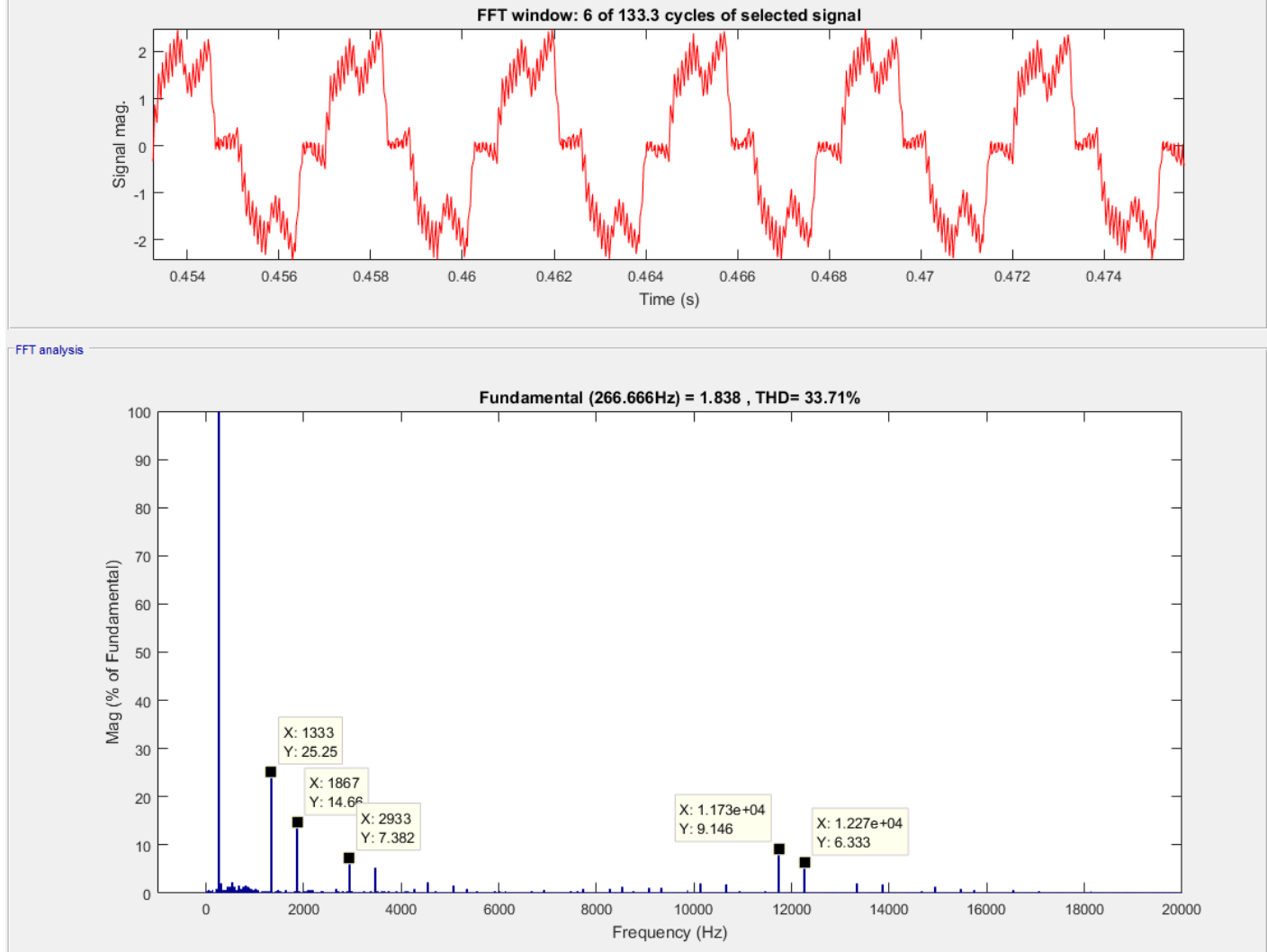

Figure 25. Time-domain representation and frequency-domain representation of a phase current for the PWM-ON-BIP modulation at no-load

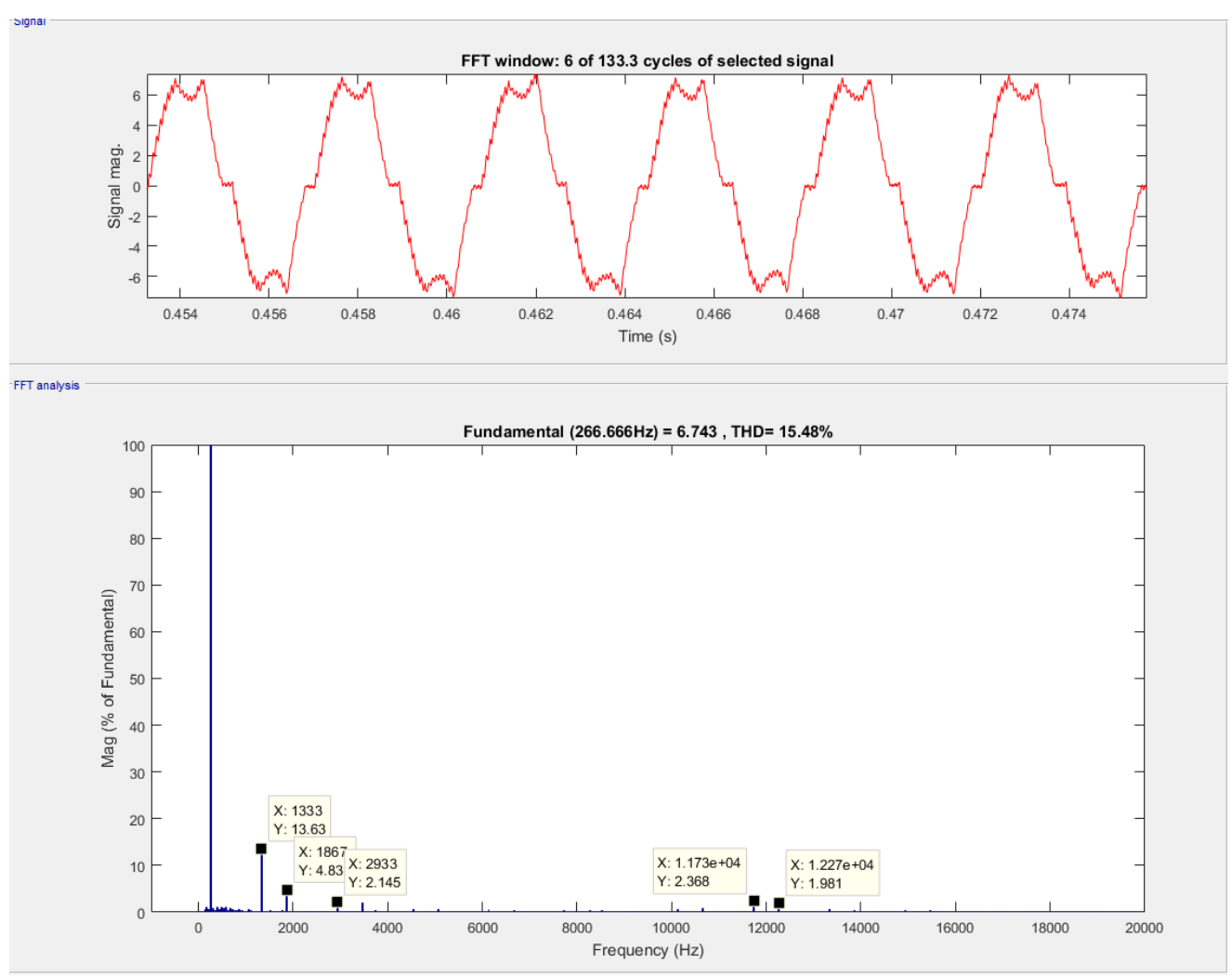

Figure 26. Time-domain representation and frequency-domain representation of a phase current for the PWM-ON-BIP modulation at $\mathrm{T}_{\text {load }}=0.076 \mathrm{Nm}$ 
Figure 27 and Figure 28 show time-domain representation and frequency-domain representation of a phase current for the non-modulating mode at no-load and $\mathrm{T}_{\text {load }}=0.076 \mathrm{Nm}$, respectively.

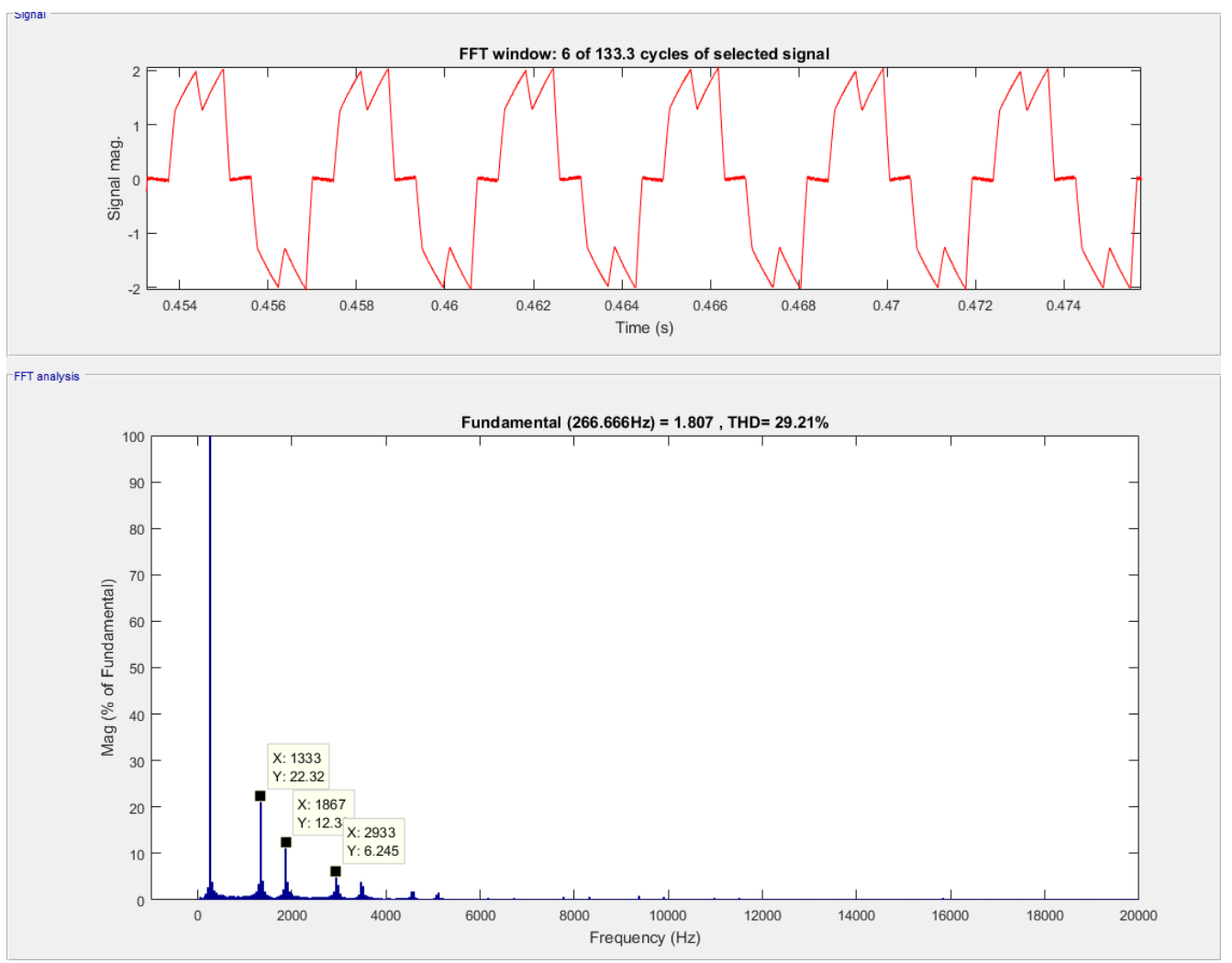

Figure 27. Time-domain representation and frequency-domain representation of a phase current for non-modulating mode at no-load

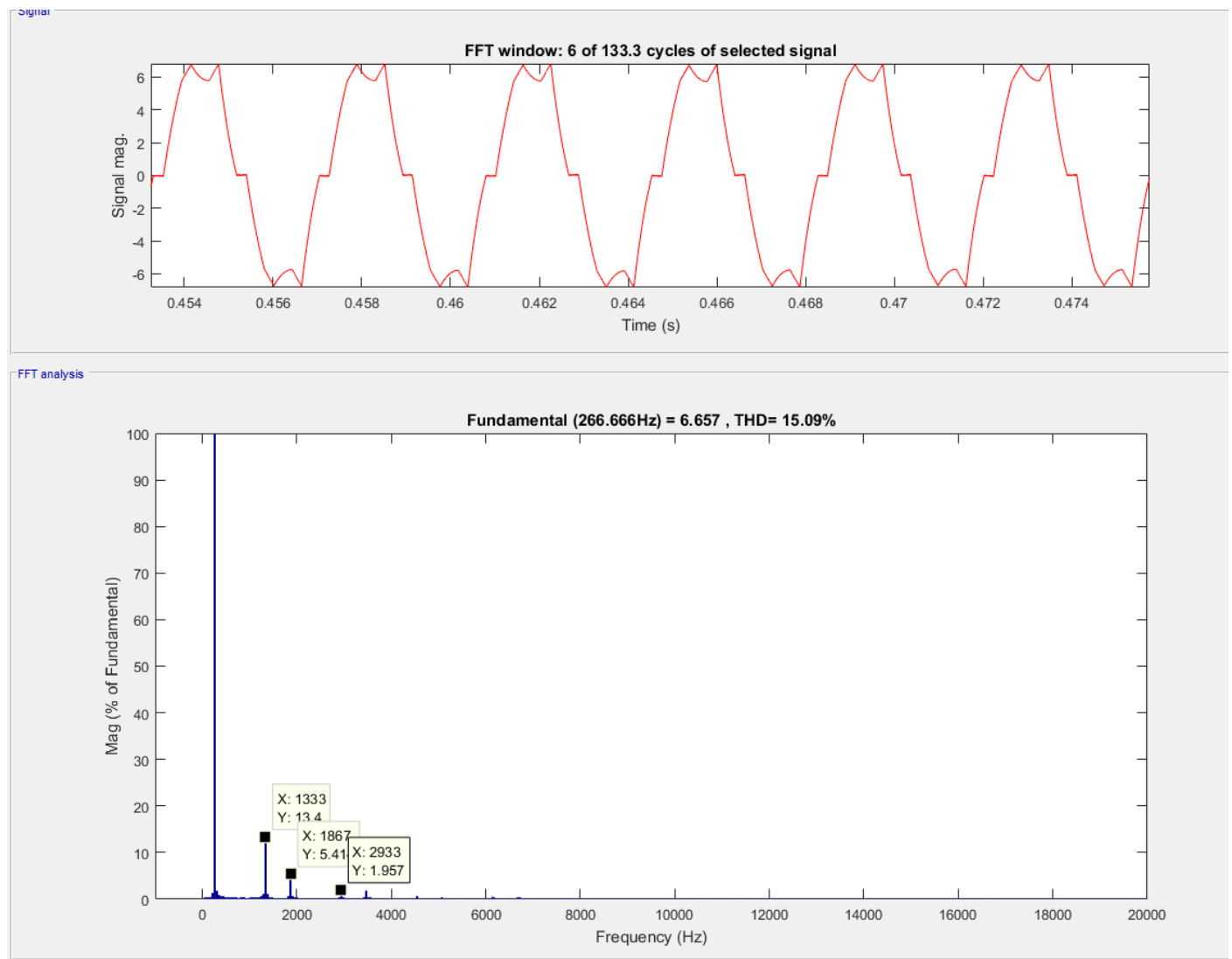

Figure 28. Time-domain representation and frequency-domain representation of a phase current for non-modulating mode at $\mathrm{T}_{\text {load }}=0.076 \mathrm{~N}$ 
With a current probe the phase currents for each modulation are measured. Figure 29 shows an experimentally measured waveform of the phase current for the PWM-ON-BIP modulation at $\mathrm{T}_{\mathrm{load}}=0.076 \mathrm{Nm}$

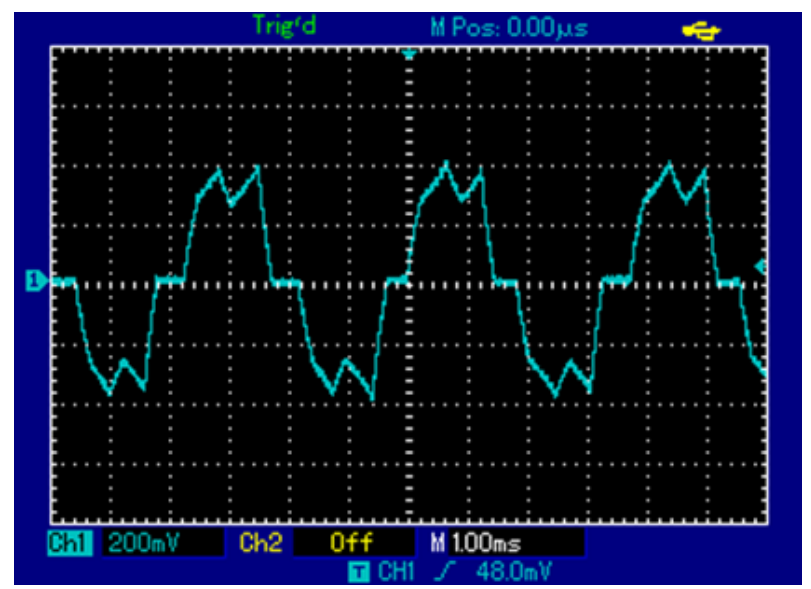

Figure 29. Experimental waveform of the phase current for the PWM-ON-BIP modulation at $\mathrm{T}_{\text {load }}=0.076 \mathrm{Nm}$

Figure 30 shows an experimentally measured waveform of the phase current for the PWM-TOP modulation at $\mathrm{T}_{\text {load }}=0.076 \mathrm{Nm}$.

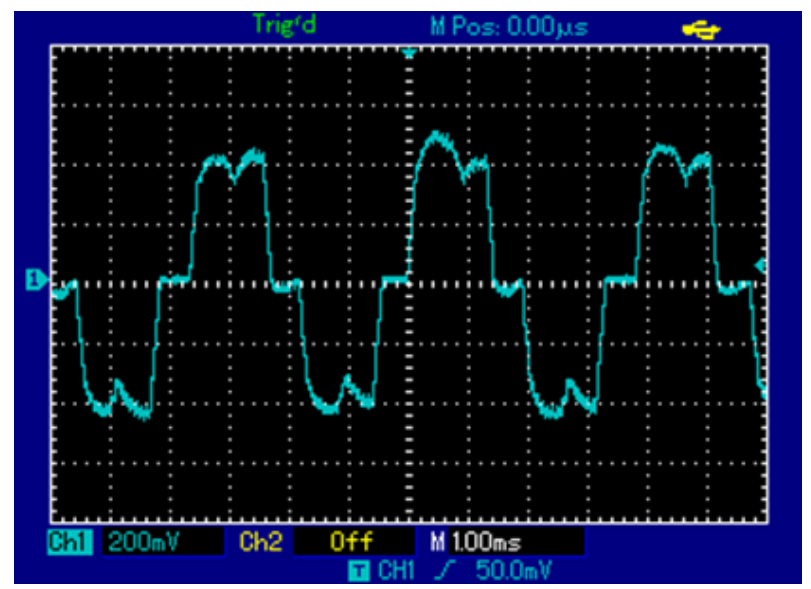

Figure 30. Experimental waveform of the phase current for the PWM-TOP modulation at $\mathrm{T}_{\text {load }}=0.076 \mathrm{Nm}$

It is known that in the ideal case, when the currents through the phase windings have rectangular waveform, the Fourier Series are of the following form:

$$
I_{a}=\frac{2 \sqrt{3} I}{\pi}\left(\sin \omega t+\frac{1}{5} \sin 5 \omega t+\frac{1}{7} \sin 7 \omega t+\cdots+n^{t h} \text { term }\right)
$$

The presence of odd harmonics and their amplitude is a prerequisite for increasing the losses in the steel.

On no load, the percentage of the odd harmonics relative to the fundamental, in each case considered, is higher than their percentage ratio at loaded motor. As the load increases, the percentage ratio drops, depending on the phase voltage duty cycle, which increases with the load.

The smaller the duty cycle the higher the ratio of the odd harmonics to the fundamental. This influences THD, causing it to increase.

Unlike the non-modulation mode, for all other used modulations, harmonics are presented symmetrically arranged around the modulation frequency $f_{m}\left(f_{m}+f_{n}\right)$ and $\left(f_{m}-f_{n}\right)$, where $f_{n}$ is the engine speed frequency $-266.6 \mathrm{~Hz}$. These components also decrease as load increases.

Table 2 represents the influence of the type of modulation techniques and motor load upon THD [\%].

Table 2. Dependence of THD [\%] from the motor load and type of modulation

\begin{tabular}{|c|c|c|c|c|}
\hline & & & THD, $(\%)$ & \\
\hline $\begin{array}{c}\mathrm{T}_{\text {load }}, \\
{[\mathrm{Nm}]}\end{array}$ & $\begin{array}{c}\text { PWM-PW } \\
\text { M }\end{array}$ & $\begin{array}{c}\text { PWM- } \\
\text { TOP }\end{array}$ & $\begin{array}{c}\text { PWM-ON } \\
\text {-BIP }\end{array}$ & Non-modulation \\
\hline 0 & 37.71 & 37.29 & 33.71 & 29.31 \\
\hline 0.02 & 31.3 & 31.33 & 26.77 & 23.77 \\
\hline 0.045 & 27.37 & 28.2 & 23.26 & 19.19 \\
\hline 0.06 & 25.09 & 25.07 & 18.59 & 16.89 \\
\hline 0.076 & 23.59 & 23.88 & 14.48 & 15.09 \\
\hline
\end{tabular}

\section{Conclusions}

Analysis is performed on the electromagnetic processes in the system battery - voltage inverter - BLDC motor for the different modulation techniques used in the control of BLDC motors. It is proven that in motor mode of operation of BLDC, the voltage inverter can be represented as a DC-DC buck converter. It is proven that by applying PWM-ON-BIP and PWM-PWM modulations the converter operates in synchronous mode.

A Matlab/Simulink model of the system is created that allows the discussed modulations to be investigated. From this model, the harmonic composition of the phase currents for each modulation is investigated. As a result of this analysis, it is proven that the no-modulation mode results in the lowest THD, and of the studied modulations with the lowest THD is PWM-ON-BIP. These results indicate that PWM-ON-BIP modulation is a good choice for use in battery powered devices and vehicles.

\section{REFERENCES}

[1] R. Krishnan. Electric Motor Drives - Modeling, Analysis, and Control. Prentice Hall, 2001

[2] R. Krishnan. Permanent Magnet Synchronous and Brushless DC Motor Drives, CRC Press, Taylor \& Francis Group 2010

[3] S. Promthong, M. Konghirun. A PWM Technique to Minimize Torque Ripple in BLDC Motor for Low-Cost Applications, 10th International Conference on Electrical Engineering/Electronics,Computer, Telecommunications and Information Technology (ECTI-CON), 2013 
[4] C. Chen, W. Chi, M. Cheng. Regenerative Braking Control for Light Electric Vehicles, IEEE PEDS 2011, Singapore, 5 - 8 December, 2011

[5] G. Krishnan, K. T. Ajmal. A Neoteric Method Based on PWM ON PWM Scheme with Buck Converter for Torque Ripple Minimization in BLDC Drive, International Conference on Magnetics, Machines \& Drives (AICERA-2014 iCMMD), Kottayam, pp.1-6, 2014

[6] J. Rong, Y. Li. The Technology Study of a new Kind of Pulse Width Modulation Mode for Eliminating Torque Ripple, International Conference on Consumer Electronics, Communications and Networks (CECNet), 16-18 April, 2011

[7] W. Salah, D. Ishak, K.Hammadi. PWM Switching Strategy For Torque Ripple Minimization in BLDC Motor, Journal of Electrical Engineering, vol. 62, No. 3, 2011

[8] B. Shengyao, M. Zhou, Z. Gao, Q. Gu, Research on Torque Ripple Modulation for Permanent Brushless DC Motor Based on DSP, IEEE 7th International Power Electronics and Motion Control Conference - ECCE Asia, 2012

[9] I. Maradzhiev, T. Grigorova, E. Dinkov. Analysis and Investigation of Methods for Energy Recovering from BLDC Motor, 9th National Conference with International Participation, ELECTRONICA 2018, Sofia, Bulgaria, 2018

[10] I. Maradzhiev, Investigation Of Types Of Modulations Used In A Converter That Drives A Brushless Dc Machine In An Electric Vehicle, Ph. D Thesis, 2018 